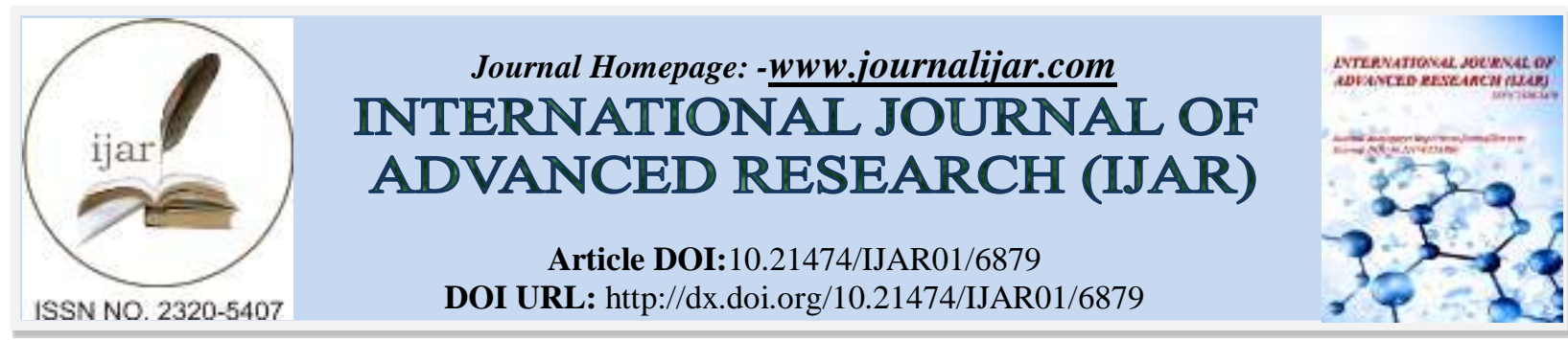

RESEARCH ARTICLE

\title{
DUAL OVULATION TRIGGERING WITH FOLLICLE-STIMULATING HORMONE AND HUMAN CHORIONIC GONADOTROPIN IN WOMEN WITH UNEXPLAINED INFERTILITY UNDERWENT LETROZOLE SUPEROVULATION AND INTRAUTERINE INSEMINATION: A RANDOMIZED CONTROLLED TRIAL.
}

\begin{abstract}
Ahmed Walid Anwar Morad.
Benha Faculty of Medicine, Farid Nada Street, Benha, Alkalubia, Egypt.

\section{Manuscript Info}

Manuscript History

Received: 07 February 2018

Final Accepted: 09 March 2018

Published: April 2018

Keywords:-

FSH, hCG, Trigger, Letrozole, Intrauterine insemination, Unexplained infertility.

Abstract

Objectives: TO determine whether a supplementary folliclestimulating hormone (FSH) bolus given at the time of the human chorionic gonadotropin (hCG) trigger can improve the pregnancy and live birth rates in women with unexplained infertility (UI) underwent letrozole stimulated intrauterine insemination (IUI). Design: A randomized controlled trial. Patients and methods: One-hundred and eight women with primary unexplained infertility underwent combined letrozole superovulation and IUI. At the time of ovulation triggering patients were randomized into hCG trigger alone (Control group) versus combined FSH plus hCG trigger (Study group). Primary outcome included the clinical pregnancy and the live birth rates. Secondary outcomes included the frequency of ovarian hyperstimulation syndrome (OHSS), multiple gestations, and abortion. Results: Significantly higher pregnancy rates pre-cycle $(12.5 \%$ vs. 5.8\%: $\mathrm{p}=0.049)$ and per-woman (33.33\% vs. $16.67 \%$ : $\mathrm{p}=0.049)$ and live birth rate $(29.6 \%$ vs. $12.5 \% ; \mathrm{p}=0.039)$ were noted in the study group compared to the control group. Abortion occurred in 2 out of 18 pregnancies $(11.11 \%)$ in the study group and in 2 out of 9 pregnancies $(22.22 \%)$ in the control group with no significant difference. No case of multiple gestations or OHSS reported in either group. Conclusion: Ovulation trigger with the dual administration of FSH and hCG compared to hCG alone significantly increased clinical pregnancy rate and the live birth rate in women with unexplained infertility underwent combined letrozole superovulation and IUI.
\end{abstract}

Copy Right, IJAR, 2018. All rights reserved.

\section{Introduction:-}

Approximately $22-28 \%$ of infertility cases are unexplained, as the basic infertility workup failed to recognize a correctable abnormality, consequently; the therapy is usually empiric. Empirical superovulation plus intrauterine insemination (IUI) is a conventional primary active therapy for women with unexplained infertility (UI) with an estimated conception rate of 8.5-21.4\%. ${ }^{[1]}$ However, Veltman-Verhulst et al. in their Cochrane review failed to identify a significant difference regarding the live birth rate in cases of UI treated with IUI without or with controlled ovarian hyperstimulation compared to timed-intercourse. ${ }^{[2]}$ The basis of stimulated IUI is to bring a large 
number of gametes to the right place and time appropriate for fertilization. Furthermore, ovarian stimulation may correct a concealed ovarian dysfunction that may underlie UI. Clomiphene citrate or gonadotropins is the standard therapy for ovarian stimulation in couples with unexplained infertility. ${ }^{[3]}$

Letrozole, a third-generation reversible aromatase inhibitor (AI), has been tested successfully as an alternative superovulation-inducing agent in ladies with UI, with the advantage of its oral intake, shorter half-life, monofollicular growth, and negligible adverse-reactions. Letrozole promotes ovulation via estrogen (E2) biosynthesis suppression. Consequently; it releases the anterior pituitary gland from the E2 negative feedback with the subsequent secretion of Follicle-Stimulating Hormone (FSH) that stimulates the ovarian follicles growth ${ }^{[4]}$. Letrozole possesses a short half-life, hence; E2 levels increased in late follicular phase and serum luteinizing hormone (LH), and FSH returned to levels equivalent to those of the nonstimulated cycles. Although, letrozole induces the release of $\mathrm{LH}$, the increase in $\mathrm{LH}$ is still well below the levels for the definition of spontaneous gonadotropins surge ${ }^{[5]}$. Luteinizing hormone surge induces resumption of oocyte meiosis and follicular rupture with subsequent growth of the corpus luteum. However, the exact role whereby FSH surge affects periovulatory events is not clearly known. ${ }^{[6,7]} \mathrm{A}$ single bolus of hCG is widely used in clinical practice for ovulation trigger and timedinsemination. If hCG is used for triggering, FSH and LH serum levels do not rise and oocyte maturation depends entirely on the LH activity of hCG. ${ }^{[8]}$ In cases of unexplained infertility; although midcycle LH surges were identifiable in most cases, the FSH surge was not a constant finding ${ }^{[8,9]}$.

The objective of this study was to appraise the impact of the concomitant administration of FSH with hCG at the time of the hCG trigger (i.e., FSH co triggering), compared with the hCG trigger alone on the pregnancy and live birth rates in ladies with primary unexplained infertility underwent letrozole superovulation and IUI.

\section{Material and Methods:-}

The protocol of this pilot randomized controlled trial was approved by the Local Ethics Committee of the Obstetrics and Gynecology Department, Benha University Hospital, and registered at Clinical Trials.gov: NCT02739516. Signed well-explained consent was taken from both partners before starting the study. The study involved 108 ladies with primary unexplained infertility selected among the attendants of the Infertility Outpatient Clinic, Benha University Hospital from June 2013 to August 2016. Inclusion criteria were ladies aged 18-35 years with normal early follicular hormonal profile (FSH, LH, prolactin, and TSH) and had primary unexplained infertility for more than 2 years evinced by normal ovulation revealed by mid-luteal serum progesterone level $>3 \mathrm{ng} / \mathrm{ml}$, patency of the fallopian tubes attested by hysterosalpingography and/or laparoscopy and adequate seminogram according to the modified WHO criteria ${ }^{[10]}$. The refusal criteria were irregular menstrual cycles, Polycystic Ovary Syndrome, endometriosis, ovarian cysts, previous IUI, day-3 FSH> $10 \mathrm{IU} / \mathrm{L}$, canceled cycles due to no or poor response to ovarian stimulation, endocrinologic maladies, systemic disease contraindicating pregnancy, liver or kidney diseases, and the used medication-related hypersensitivity.

All women took Letrozole oral tablets (Femara $2.5 \mathrm{mg}$ tablet; Novartis Pharma Services, Switzerland) $5 \mathrm{mg}$ daily from cycle day 3 to 7. Transvaginal ultrasound scan (TVS) was performed daily from cycle day 9 and 10,000 IU of hCG (Epifasi, EPICO, Egypt) was given when at least one ovarian follicle was $\geq 18 \mathrm{~mm}$ in the mean diameter. The endometrial thickness was measured on the hCG injection day in the midsagittal plane of the uterine fundus (i.e., maximum thickness point) from the echogenic interface at the endometrium-myometrium junction. On the day of hCG administration, women were randomly scheduled into two equal groups according to computer-generated random numerical tables. Envelopes containing the allocation data were selected sequentially by the patient herself in presence of the study nurse. The study group received FSH (urofollitropin; Fostimon, IBSA, Bazel, Swiz; 75 IU ampoules) $150 \mathrm{IU}$ injected on the day of hCG injection, however, the control group received hCG injection alone. Intrauterine insemination was done 36 hours following hCG injection. Ladies in both groups got luteal phase support as vaginal progesterone, (Prontogest $400 \mathrm{mg}$ Vaginal Pessaries, IBSA) twice daily, starting from the day following IUI and persisted till the eighth week if the pregnancy test was positive. Two weeks later, chemical pregnancy was diagnosed by quantitative BhCG detection. However, TVS was done 4 weeks later to ascertain a clinical pregnancy by the existence of a gestational sac with fetal heartbeats and to exclude an ectopic pregnancy. All women registered in the study underwent the study-protocol for three uninterrupted cycles unless got pregnant.

The primary outcomes were the clinical pregnancy rate calculated per cycle $(\mathrm{PR} / \mathrm{C})$ and per woman $(\mathrm{PR} / \mathrm{W})$ and the live birth rate. Secondary outcomes included the frequency of ovarian hyperstimulation syndrome (OHSS), multiple gestations, and the miscarriage rate. 


\section{Sample size calculation:-}

The sample size was estimated using online Stats To Do computer program provided that the primary outcome measure was the clinical pregnancy rate. Founded on a previous study ${ }^{[11]}$ showed a clinical pregnancy rate of $23 \%$ in women with UEI underwent letrozole stimulated IUI. We presumed a $15 \%$ increase in the clinical pregnancy rate per cycle in favor of FSH/hCG dual trigger would be of clinical significance. Thus, each group should include 147 cycles to give the study $80 \%$ power at a confidence interval of $95 \%$ using a two-tailed chi-square test with a $5 \%$ significance level (type $\alpha$ error). We presumed that the dropout incidence would be $10 \%$ and therefore 162 cycles were studied in each group. As each patient was to be treated for a maximum of 3 cycles, at least 54 women in each group were needed.

\section{Statistical design:-}

The collected Data were statistically analyzed using The Statistical Package for Social Sciences (SPSS, Chicago, USA) software version 15.0 for Windows. Numerical data were represented as the mean \pm the standard deviation, and the difference was examined using the unpaired Student $\mathrm{t}$-test. Categorical data were expressed as numbers and percentages and the difference was tested using the Chi-square test and the Relative risk at a 95\% confidence interval as appropriate. Number Needed to Treat (NNT) is the number of patients required to be treated for an extrapatient to benefit. The difference was considered statistically significant at a p-value of less than 0.05 .

\section{Results:-}

Figure 1 shows the CONSORT flowchart that represents the flow of the participants through the study stages. Patients of both groups showed no significant difference ( $>>0.05)$ as regards age, the period of infertility, body mass index and Day-3 hormonal profile (Table 1). No significant difference $(\mathrm{p}>0.05)$ between both groups was noted regarding the ovarian stimulation data including the number of the leading follicles $>18 \mathrm{~mm}$ in diameter, endometrial thickness and serum E2 levels at the time of hCG-injection (Table 2).

Pregnancy happened in 27 ladies within the three-month study period for a total pregnancy rate of $25 \%$, despite the ovulation triggering protocol. There were significantly higher clinical pregnancy rates per woman $33.33 \%$ vs. $16.67 \% ; \mathrm{p}=0.049)$ and per cycle $(12.5 \%$ vs. $5.8 \% ; \mathrm{p}=0.048)$ in favor of the $\mathrm{FSH} / \mathrm{hCG}$ trigger group compared to hCG trigger group. In FSH/hCG trigger group pregnancy distributions were 5, 8, \& 5 pregnancies during the 1st, 2nd \& 3rd cycles respectively, however; in the control group, the pregnancy distributions were 2, $3 \& 4$ pregnancies during 1 st, 2 nd $\& 3$ rd cycles respectively. The live birth rate in all studied women was $21.3 \%$ despite the ovulation triggering protocol and it was significantly higher in FSH/hCG trigger group compared to hCG trigger group $29.6 \%$ vs. 12.5\%; $\mathrm{p}=0.039)$. (Table 3) Abortion occurred in 2 out of 18 pregnancies $(11.1 \%)$ in the study group compared to 2 out of 9 pregnancies $(22.2 \%)$ in the control group with no significant difference ( $>$ 0.05$)$. The number of women needed to be treated with this FSH/hCG trigger protocol was 9, 15, and 6 to achieve an extra case of clinical pregnancy per woman and per cycle, and a live birth respectively. However, 9 women were needed to be treated with this trigger protocol to decrease abortion by one case. No case of multiple gestations, or OHSS, occurred in either arm of the study. 
Figure I:-CONSORT flowchart of participants in the trial

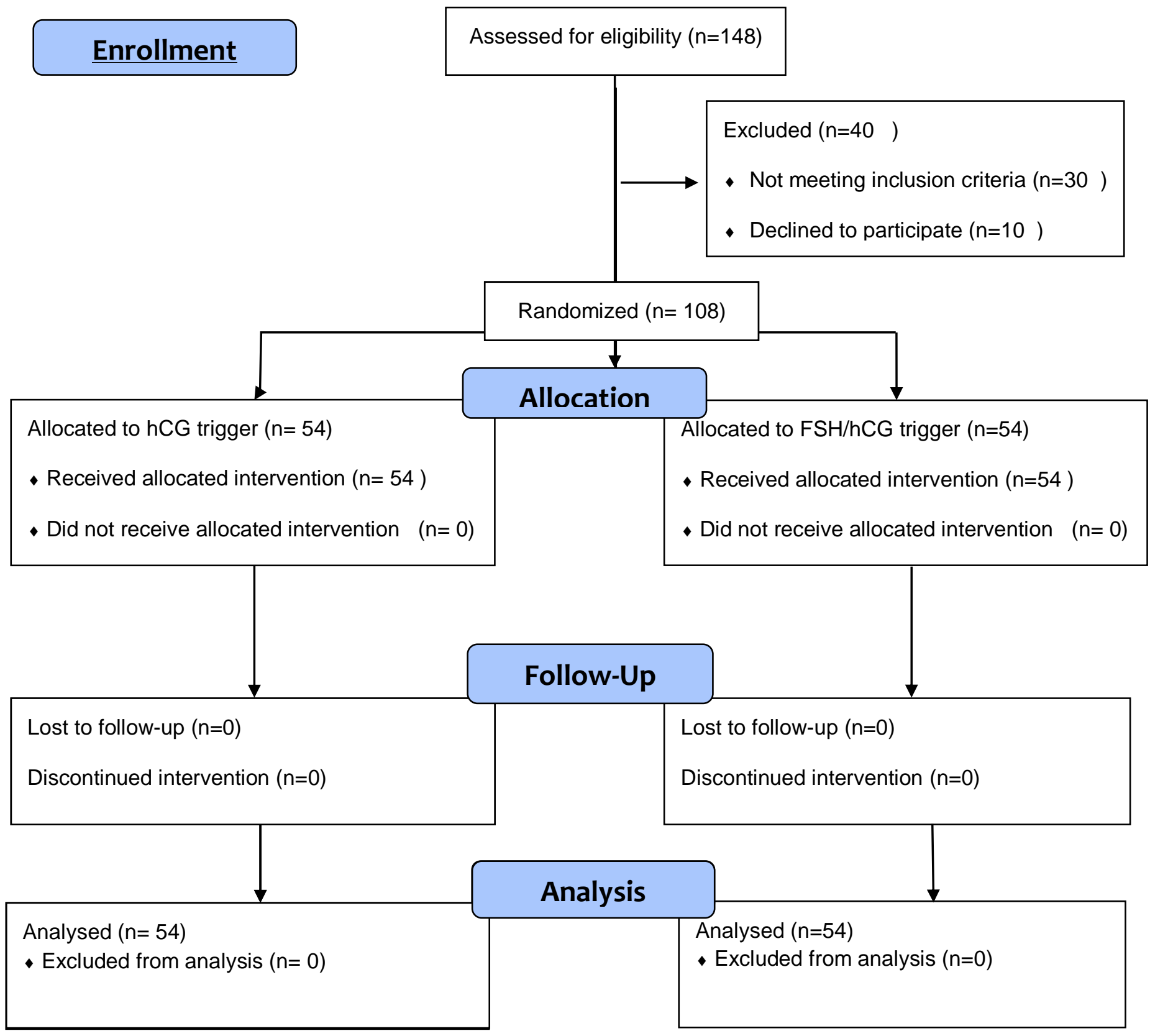


Table 1:-Patients characteristics

\begin{tabular}{|c|c|c|c|c|}
\hline \multicolumn{2}{|c|}{ Variable } & $\begin{array}{c}\text { Control group } \\
(n=54)\end{array}$ & $\begin{array}{c}\text { Study group } \\
(\mathbf{n}=54)\end{array}$ & p-value \\
\hline \multicolumn{2}{|l|}{ Age (years) } & $29.8 \pm 3.2$ & $30.4 \pm 3.3$ & 0.339 \\
\hline \multicolumn{2}{|c|}{ Duration of infertility (years) } & $2.7 \pm 0.8$ & $2.8 \pm 0.7$ & 0.491 \\
\hline \multicolumn{2}{|c|}{ BMI $(\mathrm{kg} / \mathrm{m} 2)$} & $29.5 \pm 4.1$ & $28.8 \pm 3.5$ & 0.342 \\
\hline \multirow{3}{*}{$\begin{array}{l}\text { Day-3 Hormonal } \\
\text { profile }\end{array}$} & FSH $(\mathrm{mIU} / \mathrm{ml})$ & $5.6 \pm 1.84$ & $5.41 \pm 1.75$ & 0.584 \\
\hline & LH (mIU/ml) & $4.83 \pm 1.78$ & $5.03 \pm 1.83$ & 0.566 \\
\hline & E2 (pg/ml) & $53.1 \pm 13.33$ & $50.65 \pm 12.27$ & 0.323 \\
\hline
\end{tabular}

Data are presented as mean \pm SD; BMI: Body mass index; kg/m2: kilogram per square meter; FSH: Folliclestimulating hormone; LH: Luteinizing hormone; E2: Estradiol, pg/ml: picogram/milliliter. mIU/ml: MilliInternational Units per Milliliter.

Table 2:-Comparison between the studied groups as regard to stimulation cycle characteristics

\begin{tabular}{|c|c|c|c|}
\hline Variables & $\begin{array}{c}\text { Control group } \\
(n=54)\end{array}$ & $\begin{array}{c}\text { Study group } \\
(\mathbf{n}=54)\end{array}$ & p-value \\
\hline Number of cycles completed & 155 & 144 & \\
\hline Number of follicle $>18 \mathrm{~mm}$ & $1.3 \pm 0.7$ & $1.2 \pm 0.6$ & 0.187 \\
\hline Day of hCG administration & $12.0 \pm 1.8$ & $11.9 \pm 1.7$ & 0.622 \\
\hline $\begin{array}{l}\text { Endometrial thickness (mm) on the day of FSH } \\
\text { injection }\end{array}$ & $9.5 \pm 2.1$ & $9.8 \pm 2.3$ & 0.239 \\
\hline Serum E2 level at day of FSH injection (pg/ml) & $566.5 \pm 159.4$ & $546.6 \pm 166.2$ & 0.292 \\
\hline
\end{tabular}

Table 3:-Comparison between the studied groups as regard to pregnancy outcomes

\begin{tabular}{|c|c|c|c|c|c|}
\hline Variable & $\begin{array}{c}\text { Control group } \\
(\mathrm{n}=54)\end{array}$ & $\begin{array}{l}\text { Study group } \\
(n=54)\end{array}$ & p-value & $\begin{array}{c}\text { RR } \\
(95 \% \mathrm{CI})\end{array}$ & NNT \\
\hline $\begin{array}{l}\begin{array}{l}\text { Cumulative } \\
\text { woman) }\end{array} \\
\text { PR }\end{array}$ & $9 / 54(16.67 \%)$ & $18 / 54(33.33 \%)$ & 0.049 & $\begin{array}{c}0.8 \\
(0.64 \text { to } 0.99)\end{array}$ & 9 \\
\hline PR/cycle & 9/155 (5.8\%) & $18 / 144(12.5 \%)$ & 0.048 & $\begin{array}{c}0.9289 \\
(0.8635 \text { to } 0.9994)\end{array}$ & 15 \\
\hline Live birth rate & $7 / 54(12.96 \%)$ & $16 / 54(29.6 \%)$ & 0.039 & $\begin{array}{c}0.8085 \\
(0.6610 \text { to } 0.9889)\end{array}$ & 6 \\
\hline Abortion rate & $2 / 9(22.2 \%)$ & $2 / 18(11.1 \%)$ & 0.448 & $\begin{array}{c}0.5 \\
(0.0835 \text { to } 2.9924)\end{array}$ & 9 \\
\hline
\end{tabular}

\section{Discussion:-}

The current study reported a clinical pregnancy rate of $25 \%$ and a live birth rate of $21.3 \%$ for the total letrozolestimulated cycles, regardless of the ovulation triggering protocol; the rates that accord with those formerly stated in various studies evaluated letrozole superovulation in women with UI (table 4) ${ }^{[11-16]}$. However, dual triggering by FSH/hCG compared to hCG alone improved the outcome of Letrozole-stimulated IUI cycles manifested as significantly higher pregnancy rate pre-cycle $(12.5 \%$ vs. $5.8 \%$ : $\mathrm{p}=0.049)$ and per-woman $(33.33 \%$ vs. $16.67 \%$ : $\mathrm{p}=0.049)$, and a significantly higher live birth rate $(29.6 \% \mathrm{vs}, 12.5 \% ; \mathrm{p}=0.039)$. The reported pregnancy and live birth rates in the $\mathrm{FSH} / \mathrm{hCG}$ trigger group are superior to those reported in diverse studies evaluating different letrozole-stimulated IUI protocols in women with UI (table 4) ${ }^{[11-16]}$. To our knowledge, this is the first trial planned to appraise the effect of FSH/hCG dual triggering in letrozole-stimulated cycles in ladies with UI. The reproductive benefit of FSH injection coupled with hCG trigger has been proposed in numerous studies assessing IVF cycles, their feedbacks were attributed to LH contamination in the used FSH preparations, however; it has been confirmed with the accessibility of pure recombinant human $\mathrm{FSH}^{[17]}$. In contrary other investigators ${ }^{[18,19]}$, reported that it was not beneficial to mimic the natural midcycle FSH surge in IVF cycles by giving a bolus injection of FSH. 
Table 4:-Summary of trials assessing the clinical pregnancy and live birth rates of letrozole in unexplained infertility

\begin{tabular}{|c|c|c|c|c|}
\hline Authors & $\begin{array}{c}\text { Study } \\
\text { type }\end{array}$ & Indications & Intervention & Outcome \\
\hline $\begin{array}{l}\text { Mitwally \& Casper, } \\
\text { 2003 }^{(12)}\end{array}$ & RCT & $\begin{array}{l}\text { All kinds of infertility } \\
\text { factors }\end{array}$ & $\begin{array}{l}\text { Letrozole + FSH vs } \\
\mathrm{CC}+\mathrm{FSH}\end{array}$ & CPR: $19.6 \%$ vs. $16.1 \%$ \\
\hline $\begin{array}{l}\text { Barroso, } \\
2006^{(13)}\end{array}$ & RCT & $\begin{array}{l}\text { Unexplained } \\
\text { infertility }\end{array}$ & letrozole vs CC & CPR: $23.8 \%$ vs. $20 \%$ \\
\hline Badawy, 2010 ${ }^{(14)}$ & RCT & $\begin{array}{l}\text { Unexplained } \\
\text { infertility }\end{array}$ & $\begin{array}{l}\text { letrozole + sequential } \\
\text { FSH } \\
\text { CC } \quad+\quad \text { vs } \\
\text { FSH }\end{array}$ & $\begin{array}{l}\text { CPR: } 23.7 \% \\
\text { vs } \\
26.2 \%\end{array}$ \\
\hline $\begin{array}{l}\text { Fouda \& Sayed, } \\
2011^{(15)}\end{array}$ & RCT & $\begin{array}{l}\text { Unexplained } \\
\text { infertility }\end{array}$ & $\begin{array}{l}\text { Extended letrozole } \\
\text { vs } \\
\text { CC }\end{array}$ & CPR: $18.96 \%$ Vs $11.43 \%$ \\
\hline $\begin{array}{l}\text { Ibrahim et al., } \\
2012^{(11)}\end{array}$ & RCT & $\begin{array}{l}\text { Unexplained } \\
\text { infertility }\end{array}$ & letrozole vs CC & CPR: 23.07 vs $10.68 \%$ \\
\hline $\begin{array}{l}\text { Diamond et al., } \\
2015^{(16)}\end{array}$ & RCT & $\begin{array}{l}\text { Unexplained } \\
\text { infertility }\end{array}$ & $\begin{array}{l}\text { Gonadotropin } \\
\text { vs CC } \\
\text { vs letrozole }\end{array}$ & $\begin{array}{l}\text { CPR: } 35.5 \%, 28.3 \% \text {, and } \\
22.4 \% \\
\text { LBR: } 32.2 \%, 23.3 \% \text {, and } \\
18.7 \% \text {, respectively. }\end{array}$ \\
\hline
\end{tabular}

In women with UI, it is theorized that there might be a defect in the spontaneous midcycle FSH surge. This hypothesis derived from Dmowski et al, ${ }^{[9]}$ who stated that although the midcycle LH surges were identifiable in most cases of UI, the FSH surge might be absent.

The separate but the integral roles of FSH and LH in folliculogenesis and ovulation are well-affirmed. Although LH is universally recognized as the key driver of the final oocyte nuclear maturation and the initiation of follicular rupture, the role of FSH in these processes is more controversial. ${ }^{[8]}$ Possibly, midcycle FSH surge induces plasminogen activity and promotes LH receptor formation in the luteinizing granulosa cells, nuclear maturation, and cumulus expansion. ${ }^{[20]}$ However; other investigators ${ }^{[18]}$ proposed that both FSH accumulation and cumulus oophorus complex maturation are two individualistic phenomena, each reflecting the follicle competency.

In the current study the pituitary function was preserved, therefore; the dose of supplemental FSH (150IU) was lower than that used in previous studies ${ }^{[17,18,21]}$ with pituitary down-regulation (300-450 IU). Concerning the dose of hCG trigger; $5000 \mathrm{IU}$ or 10,000 IU. The majority of studies used 10,000 IU hCG to trigger ovulation, however, both doses of hCG trigger can be utilized with approximately comparable efficacy as established by numerous randomized controlled trials in ICSI cycles ${ }^{[22.23]}$.

No significant difference was noted between both groups as regards the number of follicles $\geq 18 \mathrm{~mm}$ in diameter, endometrial thickness, and midcycle serum estradiol level as both groups received the same letrozole-stimulation protocol, however, the only difference is the method of ovulation triggering.

In the current study, no case of OHSS syndrome or multiple gestations was reported. These results agree with numerous studies reported the lower incidence of multiple gestations and OHSS in letrozole-stimulated cycles ${ }^{[11,14}$, ${ }^{15]}$. These advantages may be attributed to the short half-life of letrozole with no depletion of estrogen receptors; therefore; the normal central feedback mechanisms remain intact creating a higher probability of monofollicular growth $^{[4]}$.

There is no significant difference in the miscarriage rate between the FSH/hCG group and the hCG group with a reported abortion rate of $14.8 \%$ for the total studied cases. These rates are similar to those of spontaneous abortion in women with normal fertility ${ }^{[24.25]}$. 
The current study has some limitations: (i) non blinded; (ii) no measurement of midcycle FSH surge (iii) high cost, and (iii) the study did not incorporate an expectant management group as it is unacceptable to do so in a study concerning with infertile couples. The strengths of the current study are: (i) appropriately randomized (computerfounded) with satisfactory sample size and power calculation, (ii) the results of the study are of interest as it is the first study designed to evaluate this pilot protocol of ovulation triggering in UI in non-IVF cycles, and (iii) the live births, the main targets of infertility treatment, were evaluated as the primary outcome of the study.

\section{Conclusion:-}

Ovulation trigger with the dual administration of FSH and hCG compared to hCG alone significantly improves the clinical pregnancy rate and the live birth rate in ladies with unexplained infertility underwent combined letrozole superovulation and IUI. Further well-designed randomized large-scale trials will be required to validate these results.

\section{Acknowledgment:-}

The author thanks all participants agreed to share in this study and the staff members at the Assisted Reproduction Unit, Benha University Hospital for their help in managing the cases.

\section{Conflict of Interest:-}

None

\section{Funding:-}

No financial support for the research, authorship, and/or publication of this article had been received by the author.

\section{References:-}

1. Kamath MS, Bhattacharya S: Demographics of infertility and management of unexplained infertility. Best Pract Res Clin Obstet Gynaecol. 2012; 26(6):729-38.

2. Veltman-Verhulst SM, Hughes E, Ayeleke RO, Cohlen BJ. Intrauterine insemination for unexplained subfertility. Cochrane Database Syst Rev. 2016 Feb 19; 2:CD001838. doi: 10.1002/14651858.CD001838.pub5.

3. Kamath MS, Bhave P, Aleyamma T, Nair R, Chandy A, Mangalaraj AM, et al. Predictive factors for pregnancy after intrauterine insemination: A prospective study of factors affecting outcome. J Hum Reprod Sci 2010; 3:129-34.

4. Requena A, Herrero $\mathbf{J}$, Landeras $\mathbf{J}$ et al. Use of letrozole in assisted reproduction: a systematic review and metaanalysis. Hum Reprod Update. 2008 Nov-Dec; 14(6):571-82.

5. Bedaiwy MA, Abdelaleem MA, Hussein M et al. Hormonal, follicular and endometrial dynamics in letrozoletreated versus natural cycles in patients undergoing controlled ovarian stimulation. Reprod Biol Endocrinol. 2011 Jun $21 ; 9: 83$.

6. Hoff JD, Quigley ME, Yen SS. Hormonal dynamics at midcycle: a reevaluation. Journal Clin Endocrinol Metab 1983; 57:792-6.

7. Fauser BC, de Jong D, Olivennes F, et al. Endocrine profiles after triggering of final oocyte maturation with $\mathrm{GnRH}$ agonist after cotreatment with the GnRH antagonist ganirelix during ovarian hyperstimulation for in vitro fertilization. J Clin Endocrinol Metab. 2002; 87:709-15

8. Kol S, Humaidan P. LH (as HCG) and FSH surges for final oocyte maturation: sometimes it takes two to tango? Reprod Biomed Online. 2010 Nov; 21(5):590-2.

9. Dmowski WP, Rezai P, Auletta FJ, Scommegna A. Abnormal follicle-stimulating hormone and luteinizing hormone patterns contrasting with normal estradiol and progesterone secretion in women with longstanding unexplained infertility. J Clin Endocrinol Metab. 1981 Jun; 52(6):1218-24.

10. Cooper TG, Noonan E, von Eckardstein S. World Health Organization reference values for human semen characteristics. Hum Reprod Update. 2010; 16(3):231-45.

11. Ibrahim MI, Moustafa RA, Abdel-Azeem AA. Letrozole versus clomiphene citrate for superovulation in Egyptian women with unexplained infertility: a randomized controlled trial. Arch Gynecol Obstet. 2012 Dec; 286(6):1581-7.

12. Mitwally MF, Casper RF. Aromatase inhibition reduces gonadotrophin dose required for controlled ovarian stimulation in women with unexplained infertility. Hum Reprod 2003; 18: 1588-97. 
13. Barroso G, Menocal G, Felix H et al. Comparison of the efficacy of the aromatase inhibitor letrozole and clomiphene citrate as adjuvants to recombinant follicle-stimulating hormone in controlled ovarian hyperstimulation: a prospective, randomized, blinded clinical trial. Fertil Steril. 2006 Nov; 86(5):1428-31.

14. Badawy A, Elnashar A, Totongy M. Clomiphene citrate or aromatase inhibitors combined with gonadotropins for superovulation in women undergoing intrauterine insemination: a prospective randomised trial. J Obstet Gynaecol. 2010; 30(6):617-21.

15. Fouda UM, Sayed AM. Extended letrozole regimen versus clomiphene citrate for superovulation in patients with unexplained infertility undergoing intrauterine insemination: a randomized controlled trial. Reprod Biol Endocrinol 2011; 9: 84.

16. Diamond MP, Legro RS, Coutifaris C et al. Letrozole, Gonadotropin, or Clomiphene for Unexplained Infertility. N Engl J Med. 2015 Sep 24; 373(13):1230-40.

17. Lamb JD, Shen S, McCulloch C et al. Follicle-stimulating hormone administered at the time of human chorionic gonadotropin trigger improves oocyte developmental competence in in vitro fertilization cycles: a randomized, double-blind, placebo-controlled trial. Fertil Steril. 2011 Apr; 95(5):1655-60.

18. Vermeiden JP, Roseboom TJ, Goverde AJ, Suchartwatnachai C, Schoute E, Braat DD, Schats R. An artificially induced follicle stimulating hormone surge at the time of human chorionic gonadotrophin administration in controlled ovarian stimulation cycles has no effect on cumulus expansion, fertilization rate, embryo quality and implantation rate. Hum Reprod. 1997 Jul; 12(7):1399-402.

19. Juneau CR, Morin SJ, Franasiak JM, Landis JN, Molinaro TA, Scott RT. A 'follicle-stimulating hormone boost' administered at the time of human chorionic gonadotropin trigger does not affect IVF cycle outcomes. Fertil Steril. 2016; 106(3): e189-e190

20. Yding Andersen C. Effect of FSH and its different iso-forms on maturation of oocytes from pre-ovulatory follicles. Reprod Biomed Online 2002; 5(3):232-9.

21. Bianchi V, Dal Prato L, Maccolini A, Mazzone S, Borini A. Inadvertent recombinant human follicle stimulating hormone bolus instead of human chorionic gonadotrophin leads to the retrieval of competent oocytes in IVF program. Fertil Steril. 2009 Nov; 92(5):1747.e1-3. doi: 10.1016/j.fertnstert.2009.07.998. Epub 2009 Sep 3.

22. Abdalla HI, Ah-Moye M, Brinsden P, Howe DL, Okonofua F, Craft I, The effect of the dose of human chorionic gonadotropin and the type of gonadotropin stimulation on oocyte recovery rates in an in vitro fertilization program, Fert. Steril. 48 (6): 1987; 958-963.

23. Shaltout AA, Eid MS, Shohayeb AA. Does triggering ovulation by 5000 IU of uhCG affect ICSI outcome?, Middle East Fert Soc. J. 11 (2): 2006; 99-103.

24. Wilcox AJ, Baird DD, Weinberg CR. Time of implantation of the conceptus and loss of pregnancy. N Engl J Med 1999; 340: 1796-1799.

25. Pezeshki K, Feldman J, Sten DE, Lobel SM, Grazi RV. Bleeding and spontaneous abortion after therapy for infertility. Fertil Steril 2000; 74: 504-508. 